\title{
Do Feedback Environment and Coaching Communication Determine Self-Efficacy of Teaching? A Case of Malaysian Polytechnic Lecturers
}

\author{
Ying-Leh Ling
}

Universiti Sains Malaysia, Malaysia

Abdul Ghani Kanesan Abdullah
Universiti Sains Malaysia, Malaysia

\begin{abstract}
:
This quantitative descriptive study aimed to identify the influence of coaching communication on the relationship between feedback environment and self-efficacy of teaching. In particular, the objective of this study was to identify whether the coaching communication would be able to become a mediator in the relationship between feedback environment and self-efficacy of teaching. A total of 411 lecturers randomly selected from the five three polytechnics which successfully obtained an overall excellent performance including academic standards and quality management through the recognition of the polytechnic ratings. Data for this survey were collected through a questionnaire which was adapted from literature review (Steelman et al., 2004; Heslin et al., 2006; Tschannen-Moran and Hoy, 2001). The results of multiple regression analysis showed that feedback environment and coaching communication had positive and significant influence on self-efficacy of teaching. In addition, feedback environment also had an impact on all dimensions of coaching communication. Meanwhile coaching communication acts as a full mediator on the relationship between feedback environment and self-efficacy of teaching. In term of the implications, this study showed the role of the middle manager is extremely important in creating the feedback environment in the workplace in order to improve coaching communication performance.
\end{abstract}

Paper type: Research paper

Keywords: Feedback Environment, Technical Education and Vocational Training, Coaching Communication, Self-Efficacy of Teaching 


\section{Introduction}

For Malaysia to become a high-income nation by the year 2020, it is imperative to produce a competent workforce to compete in an intensified global market. The Economic Transformation Programme which was introduced in 2010 is projected to create over 3 million new job openings by 2020, of which at least 40 percent is expected to obtain Technical Education and Vocational Training (TVET) qualifications (Performance Management and Delivery Unit, 2011). In relation to that, TVET has been regarded as one of the most significant drivers for the country to transform from a middle-income country to a high-income nation. The needs of skilled workforce would not be met if there is an absence of proficient educators to provide quality learning environment.

The management of vocational education in Malaysia has undergone a series of changes. First, the Department of Polytechnic and Community College Education (DPCCE) was formed in 2004 which altered the system of governance (Department of Polyteclinic and Community College Education, 2014). According to Economic Planning Unit (2015), there are 525 public training institutions under seven ministries including Ministry of Education, Ministry of Human Resources, Ministry of Youth and Sports, Ministry of Regional and Rural Development, Ministry of Agriculture and Agro-Based Industry, Ministry of Works, and Ministry of Defence. Furthermore, a number of vocational training institutes were established with the cooperation of Germany, France, and Japan (Mustapha, 2001). These training institutions offer similar courses and the overlapped course offerings result in duplication and wastage of resources (Economic Planning Unit, 2015) which calls for a better coordination of resources. Consequently, the changes in governance and increased accountability for academic performance all affect the performance management system in vocational education colleges (Briggs, 2004).

In facing the increasingly competitive and fast-changing business environment, the ability to learn and adapt quickly has become an essential skills. In relation to that, there is a need for organisations to find a solution that can both increase organisational effectiveness and retain talented people. The development needs of each individual are varied and thus it is imperative for organisations to recognise the importance of a more personal and responsive development approach. Coaching and performance feedback seem to be a useful tool for organisations in this regard. This argument is supported by a number of empirical evidence which found that performance feedback is one of the statistically significant predictors of task mastery (Jex and Britt, 2008) and job performance (Ilgen and Moore, 1987; Kluger and DeNisi, 1996; Sommer and Kulkarni, 2012). Furthermore, both performance feedback and self-efficacy are found to be the necessary conditions for goal-setting to be effective (Jex and Britt, 2008). This is because employees will not be able to achieve their personal goals and organisational objectives without sufficiently detailed feedback regarding the extent to which their performances are contributing to the overall targets.

Over recent years, there has been an increasing trend of organisations taking greater responsibility for developing their human capital. Many organisations perceive coaching as a developmental tool for their staff as well as a strategic initiative to improve both individual and organisational performance (Bowen and Schofield, 
2013). Coaching involves collaborative and effective two-way communication between coach and coachee. Thus, middle managers play a significant role in supporting personal development as well as improving job performance (Stewart and Palmer, 2009). Ideally, coachees receive direct advice and attention which fits with their career developmental goals. Combining these together, continuous supports for personal development plans -- namely feedback environment and coaching communication -- is believed to have positive influence to the formation of an individual's self-efficacy. Educators with strong self-efficacy beliefs are more likely to choose a strategy to effectively address the tension and persistent in the tasks entrusted (Zajacova et al., 2005).

The studies on self-efficacy of teaching are mainly conducted in school settings and there is little work have been done in researching self-efficacy of teaching in further and higher education institutions. For this reason, this paper aims to understand the dynamics of perceived self-efficacy in further education, with a special focus on the influence of coaching and feedback to self-efficacy of teaching.

\section{Literature Review}

\subsection{Self-Efficacy of Teaching}

Individuals who have great level of self-efficacy tend to be highly motivated and confident to perform the tasks entrusted to it (Gibson and Dembo, 1985). Self-efficacy also influences the actions of individuals in the field of work, the extent of its business and holds its resilience in the face of adversity (Tschannen-Moran and Hoy, 2001). A college teacher may be confident when teaching in familiar environment but may feel uncertain regarding his or her ability to perform well in uncertain circumstances. This is in line with the views of Tschannen-Moran et al. (1998) which maintain confidences in the teachers need to take a series of behaviour in specific situations and structured teaching. Following this line of thought, self-efficacy of teaching revolves around the ability of educators to establish a positive effect on student achievement through teaching and learning curriculum that has been set.

Self-efficacy of teaching also includes the ability to improve teaching strategies from time to time and increase the added value of the knowledge gained. For that reason, teachers with high level of self-efficacy are more likely to perform better compared to those with lower level of self-efficacy. According to Hoy and Tschannen-Moran (2003), the self-efficacy of teachers is the action done by the teachers in certain situations rather than what has been achieved by them or why they need to be achieved. This is because self-efficacy of teachers influences the actions, the mindset and emotional reaction to the situation at hand. Thus, by taking into accounts the views of Hoy and Tschannen-Moran (2003), in this research, self-efficacy of teaching refers to the ability of the educators to implement instructional strategies, classroom management, and engaging students in the learning process.

\subsection{Feedback Environment}

The significance of performance feedback in an organisation is well supported by scholars come from many different disciplines including performance management (Aguinis et al. 2012; Broad and Goddard, 2010; Levy and Williams, 2004), human 
resource development (Nae et al., 2015; Sommer and Kulkarni, 2012; Young and Steelman, 2014), and organisational studies (Chen et al., 2007; Westerman et al., 2014). The usefulness of feedback depends on a series of contextual factors including the consistency in delivery (Westerman et al., 2014), the perceived quality of the feedback (Ilgen and Moore, 1987; Kluger and DeNisi, 1996; Nae et al., 2015), and the credibility of feedback giver (Bozer et al., 2014; Nae et al., 2015; Steelman et al., 2004). The concept of feedback environment revolves around feedback-seeking behaviour, the process of feedback-giving, and the attitudes towards received feedback.

This study used Feedback Environment Scale proposed by Steelman et al. (2004) which consists of six facets: the credibility of the feedback source, the quality of feedback, feedback delivery, constructive feedback, feedback availability, and encourage feedback seeking. Each component of the feedback environment will be discussed in the following.

Feedback credibility refers to the trustworthiness and expertise of the feedback provider as perceived by the coachee (Bozer et al., 2014). Empirical studies found that the credibility of a coach is positively related to coaching effectiveness (Bozer et al., 2014; Boyce et al., 2010; Fedor et al., 1989; Nae et al., 2015). Mainly, this is due to the phenomenon that people generally respond positively to feedback when the source of feedback is credible and competent (Steelman et al., 2004).

The second element of feedback environment is the content of feedback, which includes feedback quality and constructive feedback. For feedback to be helpful, it should be accurate, specific, and constructive (Steelman et al., 2004). The relationship between high quality feedback and work performance is well established (Ilgen and Moore, 1987; Kluger and DeNisi, 1996; Sommer and Kulkarni, 2012). By contrast, Nae et al. (2015) found that there is no improvement in individual performance if the employee received low quality performance feedback from their supervisor. Constructive feedback should be a combination of praise and criticism regarding the performance of workers (Aguinis et al. 2012). In other words, for feedback to be meaningful, the feedback should indicate areas of improvement in addition to giving recognition to good performance. The rationale of strength-based approach is to continuously develop the personal strengths of the employees rather than overcome their weaknesses (Buckingham and Clifton, 2001).

A closely relevant component to the content of feedback is feedback delivery. In this study, feedback delivery refers to the process and methods of delivering feedback. Face-to-face communication is often seen as an effective means of disseminating annual performance appraisal (Westerman et al., 2014) and yet the rise of globally dispersed workforces and increasing demand for timely feedback led to an increasing use of e-mails as a common medium to deliver feedback (Cox et al., 2011). The emphasis of feedback delivery is put on the tone and intention of the feedback giver (Steelman et al., 2004) irrespective of the type of media being used. In particular, some managers are reluctant to deliver negative feedback (Westerman et al., 2014) and may 'sugarcoat' their feedback (Cox et al., 2011), thus making the feedback less accurate. 
Another influential factor of feedback environment is the availability of feedback. To a great extent, access to feedback can help individuals to deal with uncertainties (DeRue and Wellman, 2009), which subsequently increase self-efficacy in handling challenging tasks. Access to feedback allows individuals to have better understanding of their competency and performance (Kluger and DeNisi, 1996). On the contrary, the absence of feedback represents a developmental challenge. Broad and Goddard (2010) found that the absence of formal feedback reporting system in higher education institutions resulting a lack of accountability of the performance management system.

The last component of feedback environment is 'encouragement of feedback-seeking'. Responsibilities of $21^{\text {st }}$ century managers include coaching their subordinates and encourage feedback-seeking behaviour at work (Steelman et al., 2004). This statement is in line with the study of Chen et al. (2007) which remarked that organisations should create an approachable channel which allows their employees to seek feedback, including the nnegative feedback, from their supervisors. Williams et al. (1999) noted that encouragement of feedback-seeking behaviour has an impact on the frequency of workers seeking feedback from their supervisor. Studies found that feedback-seeking behaviour has mediating effect to adapt in a new working environment (Morrison, 1993; Wanberg and Kammeyer-Mueller, 2000).

Taken these together, the feedback environment as defined by Steelman et al. (2004) is a multifaceted contruct which reflect the contextual aspects of work-related feedback. The provision of performance feedback is particularly vital for early-career teaching staff. Shannon et al. (1998) noted that Graduate Teaching Assistants (GTA) have limited opportunities to receive feedback regarding their teaching and thus continued to teach ineffectively. And thus there is a need for the inexperienced teaching staff to receive feedback from the experienced academic staffs.

Hypothesis 1: Feedback environment is positively related to self-efficacy of teaching.

Hypothesis 2: Feedback environment is positively related to coaching communication.

\subsection{Coaching Communication}

Coaching is a developmental technique that is essentially based on one-to-one discussion in order to enhance job performance. Typically, coaching involves setting both personal and organisational goals with a special emphasis on improvement at work. Coaching is also about inspiration and encouragement (Berg and Karlsen, 2012; Heslin et al., 2006). Coaching has the adaptability to accommodate and support different learning styles since coaching is more personalised than other developmental methods such as training and seminar which are typically designed to deliver at greater scale (Spry, 2010). In the context of this review, coaching communication refers to the behaviour of the supervisors to improve performance through bilateral interaction with intention to accomplish career goals and organisational objectives.

The coaching role of managers in further and higher education institutions is often overlooked. Bowen and Schofield (2012) proposed coaching as a learning and development intiative in tertiary education institutions because coaching promotes employee engagement by empowering staff and giving more responsbility to them. This is in accordance with the functions of the Department of Polytechnic Education 
in Malaysia: to plan and execute staff training and career development programmes and to plan and develop quality assurance and a control system (Department of Polyteclinic and Community College Education, 2014).

Based on the work of Heslin et al. (2006), three main functions of coaching are used to investigate the process of coaching communication in the context of Malaysian polytechnics, and these include: facilitating learning, inspiring others, giving job guidance. Early career teaching staff often lacks necessary experience to perform their instructional roles (Shannon et al. 1998). Job guidance from a more experienced academic staff could facilitate learning and inspiring self-efficacy towards teaching.

Hypothesis 3: Coaching communication is positively related to self-efficacy of teaching.

Hypothesis 4: Coaching communication has the mediating effect on the relationship between feedback environment and self-efficacy of teaching.

\section{Research Framework and Research Objectives}

Briggs (2004) observed a "new professionalism" in further education colleges, where middle managers or line-managers are responsible for improving staff performance. In Malaysia, there is a lack of recognition for vocational instructors (Economic Planning Unit, 2015; Mustapha, 2001). Moreover, the teaching staffs at Malaysian polytechnics typically have limited industrial experiences and in-service training (Mustapha, 2001). When asked to make suggestions to improve vocational education in Malaysia, vocational educators have recommended professional development as top priority (Mustapha, 2001). Without the necessary training, the vocational educators must learn from on-the-job experience. The managers in further education colleges play an important role in this regards since they are responsible for giving job guidance and supporting developmental needs of individual teaching staffs (Briggs, 2004). Coaching would be an effective performance improvement technique and the regular feedback from the coachee can facilitate continuous performance improvement. The presence of feedback environment enables employees to continuously develop themselves (Levy and Williams, 2004; Steelman et al., 2004) and perhaps outperform managerial expectation.

As mediator variables, coaching communication can be tested to measure the direct effect or indirect effect on the relationship between feedback environment and selfefficacy of teaching. This statement is in line with the views of Berg and Karlsen (2012) who maintain that coaching can help to unlock the potential of individuals and inspire them to accomplish career goals as well as facilitate continuous learning on the job.

Therefore, this conceptual framework consists of three variables, namely feedback environment, coaching communication, and self-efficacy of teaching. In this study, feedback environment refers as an independent variable, coaching communication as mediator variable while the self-efficacy of teaching is the dependent variable (see Figure 1). 
Do Feedback Environment and Coaching Communication Determine Self-Efficacy of Teaching? A Case of Malaysian Polytechnic Lecturers

Figure 1: A priori structural model

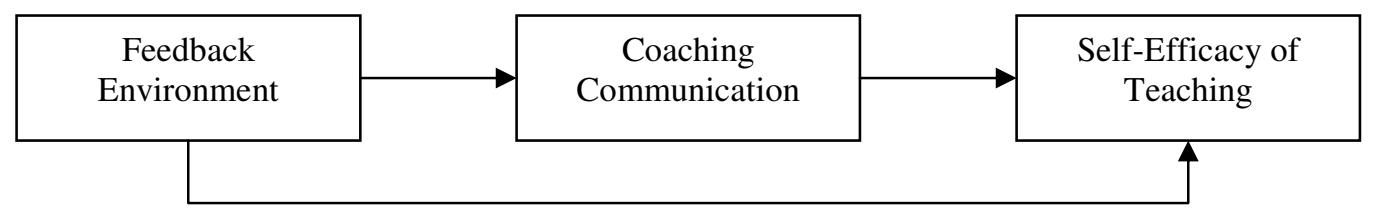

\section{Research Methodologies}

The study was conducted using a survey method. Sampling consisted of 411 lecturers who are serving in the five polytechnics which successfully obtained an overall excellent performance including academic standards and quality management through the recognition of the polytechnic rating. The instrument used was a questionnaire which was adapted from the feedback environment scale (Steelman et al., 2004), coaching behaviour scale Heslin et al. (2006), and efficacy subscale (TschannenMoran and Hoy, 2001). The questionnaire is divided into four parts namely Part A to obtain demographic information of respondents, Part B (25 items) also diagnose the extent of organization support on feedback process, Part C (12 items) to measure the behaviour of a leader in helping followers to improve performance and developing the potential of employees, and Part D (9 items) on the perception of lecturers on selfefficacy of teaching. A total of 600 questionnaires were distributed and 411 questionnaires only be collected with the questionnaire return rate as high as 68.5 percent.

\section{Research Findings}

\subsection{Respondent Profile}

The respondents consisted of 411 lecturers who taught at the polytechnic Malaysia. Descriptive statistical analysis of frequencies and percentages were used to describe the profile of the respondents that include gender, the highest academic qualifications, academic department category, teaching experience, and age on January 1, 2014.

Table 1: Respondent Profile (N=411)

\begin{tabular}{llcc}
\hline Variables & Categories & Frequency & Percentage \\
\hline Gender & Male & 151 & 36.7 \\
Academic & Female & 260 & 63.3 \\
Qualification & Certificate/Diploma & 16 & 3.9 \\
& Bachelor degree & 244 & 59.4 \\
& Master degree & 145 & 35.3 \\
Academic Department & Doctorate degree & 6 & 1.5 \\
& Humanities and Social Sciences & 183 & 44.5 \\
& Technical & 205 & 49.9 \\
Teaching Experience & Communication \& Information Technology & 23 & 5.6 \\
& $1-9$ years & 213 & 51.8 \\
& $10-18$ years & 142 & 34.5 \\
& $19-27$ years & 45 & 10.9 \\
Age on 1 January 2014 & $28-36$ years & 12 & 2.6 \\
& 25-33 years & 188 & 45.7 \\
& 34-42 years & 151 & 36.7 \\
& $43-51$ years & 56 & 13.6 \\
& 52 years and above & 16 & 3.9 \\
\hline
\end{tabular}

International Journal of Management and Applied Research, 2015, Vol. 2, No. 2 
To determine the level of communication practice guidance, the three-dimensional coaching communication of facilitating, inspiration, and job guidance has shown moderate mean scores between 4.64 and 4.95. Coaching communication overall mean score as high as 4.83 , which is moderate. For self-efficacy of teaching variable, there is as high as mean score 5.66 of a scale of 1 to 7 . The three-dimensional self-efficacy of teaching including efficacy in classroom management, efficacy in student engagement, and efficacy in instructional strategies those are beyond the mean score 5.60 which considered high level.

Table 2: Mean Score and Standard Deviation

\begin{tabular}{lcc}
\hline Variables & Mean $(\mathbf{M})$ & Standard Deviation (SD) \\
\hline Feedback Environment & 5.42 & .77 \\
Feedback Source Credibility & 5.70 & .83 \\
Feedback Quality & 5.67 & .83 \\
Feedback Delivery & 5.37 & .98 \\
Feedback Source Availability & 5.31 & 1.00 \\
Constructive Feedback & 5.17 & 1.00 \\
Encourage Feedback Seeking & 5.27 & 1.08 \\
Coaching Communication & 4.83 & 1.20 \\
Facilitating & 4.89 & 1.21 \\
Inspiration & 4.95 & 1.24 \\
Job Guidance & 4.64 & 1.39 \\
Self-Efficacy of Teaching & 5.66 & .74 \\
Efficacy in classroom management & 5.64 & .86 \\
Efficacy in student engagement & 5.73 & .80 \\
Efficacy in instructional strategy & 5.60 & .83 \\
\hline
\end{tabular}

\subsection{Feedback Environment}

Multiple regression analysis was used to measure the contributions or responses of feedback environment on coaching communication. Multiple regression results indicate significant feedback environment responses each accounted for 47 percent of the variance changes the coaching communication and 6 percent of the variance change self-efficacy of teaching. Hypothesis 1 was supported; feedback environment is positively related to self-efficacy of teaching $(\beta=.25, p<.05)$. Hypothesis 2 was supported; feedback environment is positively related to coaching communication $(\beta=.68, p<.05)$.

Table 3: Influence of feedback environment on coaching communication and self-efficacy of teaching

\begin{tabular}{lcc}
\hline Variable & Coaching Communication & Self-Efficacy of Teaching \\
\hline Feedback Environment & .68 & .25 \\
$\mathrm{R}^{2}$ & .47 & .06 \\
Adjusted $\mathrm{R}^{2}$ & .46 & .06 \\
F Value & $354.24 *$ & $27.11^{*}$ \\
Durbin Watson & 1.67 & 1.90 \\
\hline Note: $* p<.05$ & &
\end{tabular}

\subsection{Coaching Communication}

The results of Table 4 shows the results of multiple regression analysis performed on self-efficacy of teaching and coaching communication variables. The decision found 
that the coaching communication has significantly contributed 11 percent of the variance changes for self-efficacy of teaching. The assessment of the value of the beta coefficient $(\beta)$ indicates the coaching communication has a positive effect on the efficacy of teaching $(\beta=.33, p<.05)$. Therefore, Hypothesis 3 was supported.

Table 4: Influence of Coaching Communication on Self-Efficacy of Teaching

\begin{tabular}{lc}
\hline Variable & Self-Efficacy of Teaching \\
\hline Coaching Communication & .33 \\
$\mathrm{R}^{2}$ & .11 \\
Adjusted $\mathrm{R}^{2}$ & .11 \\
F Value & $50.96^{*}$ \\
Durbin Watson & 1.86 \\
\hline Note: ${ }^{*} p<.05$ &
\end{tabular}

\subsection{Mediating Effect of Coaching Communication}

Hypothesis 4 was supported; coaching communication partially mediated the effect of feedback environment on self-efficacy of teaching, based on guidelines set forth by Baron and Kenny (1986) for testing mediation. The regression coefficients in table 3 and 4 show that coaching communication is significantly (and positively) related to feedback environment (Independent Variable) self-efficacy of teaching (Dependent Variable), thus meeting the conditions for mediation (Mediator Variable is significantly related to the Independent and Dependent Variables). The beta coefficient for feedback environment, which was significant in the first analysis (see table 3), is now no longer significant when controlling for the effects of the Mediator Variable, coaching communication (see table 5). Thus the final condition for demonstrating mediation has also been met.

Table 5: Mediating Effect of Coaching Communication

\begin{tabular}{|c|c|c|c|}
\hline \multirow[t]{2}{*}{ Variable } & \multicolumn{3}{|c|}{$\begin{array}{c}\text { Dependent Variable } \\
\text { Self-Efficacy of Teaching (DV) }\end{array}$} \\
\hline & $\mathrm{DV}(\beta)$ & DV without MV $(\beta)$ & DV with MV $(\beta)$ \\
\hline \multicolumn{4}{|l|}{ Independent variable (DV) } \\
\hline Feedback Environment & - & $.21 *$ & .07 \\
\hline \multicolumn{4}{|l|}{ Mediator variable (MV) } \\
\hline Coaching Communication & $.29 *$ & - & $.25^{*}$ \\
\hline $\mathrm{R}^{2}$ & .09 & .05 & .09 \\
\hline Adjusted $\mathrm{R}^{2}$ & .08 & .04 & .08 \\
\hline F Value & $36.19 *$ & $18.13^{*}$ & $18.96^{*}$ \\
\hline Durbin Watson & 1.89 & 1.94 & 1.89 \\
\hline
\end{tabular}

\section{Discussion and Research Implication}

The findings show that feedback environment has a positive impact on coaching communication $(\beta=.68, p<.05)$ and self-efficacy of teaching $(\beta=.25, p<.05)$. Coaching communication was also found to have a positive impact on self-efficacy of teaching $(\beta=.33, p<.05)$. The hypothesised structural model was a mediated model consisting of paths between feedback environment, coaching communication, and self-efficacy of teaching, where coaching communication was proposed to mediate the effect of feedback environment on self-efficacy of teaching (see Figure 2). 
Do Feedback Environment and Coaching Communication Determine Self-Efficacy of Teaching? A Case of Malaysian Polytechnic Lecturers

Figure 2: Mediation model including the regression coefficients

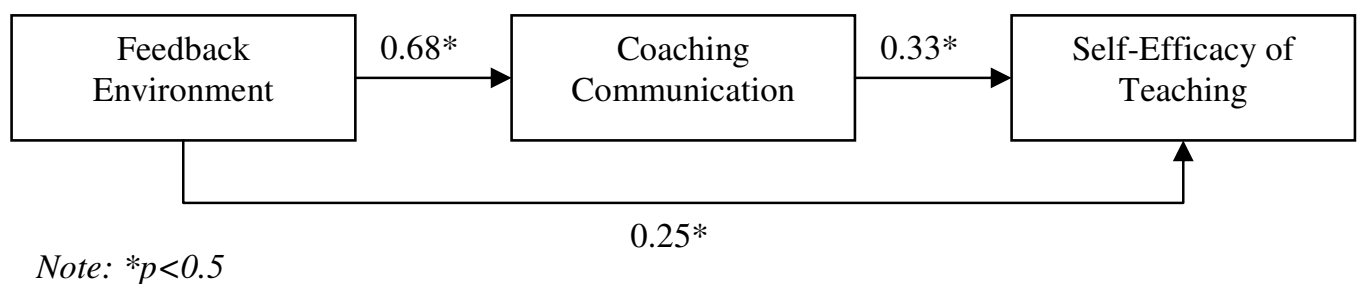

The feedback environment contributes 6 percent to the variance change in selfefficacy of teaching and contributes 47 percent to the variance change in coaching communication. The finding is in line with the findings Young and Steelman (2014) and Whitaker and Levy (2012) in which feedback environment will enable individuals to find useful information about their work performance so that they can achieve a better understanding about themselves and managerial expectations.

In addition, the coaching communication also contributes 11 percent to the variance changes in self-efficacy of teaching. This finding is consistent with the study of Thach (2002) in which coaching helps people in achieving the goals set for improving organisational productivity and personal satisfaction. Similarly, Bandura and Cervone (1986) also concluded that coaching is considered as a form of social persuasion in which people are guided by recommendations to believe they can successfully cope with the given tasks. Therefore, the middle managers, especially those who are responsible of developing teaching staff, should establish and maintain positive coaching communication to increase self-efficacy in teaching.

\section{Conclusion}

This study attempts to show the influence of feedback environment and coaching communication on self-efficacy of teaching. In addition, as a pioneer it is to study the role played by coaching communication as a mediator in educational organizations of Malaysia. The results of this study show that feedback environment is positively related to coaching communication and self-efficacy of teaching. In addition, the coaching communication also affects the relationship between feedback environment and self-efficacy of teaching. Therefore, according to the findings of the current study, middle managers in polytechnics should demonstrate their commitment to create feedback environment in order to improve lecturers' confidence and ability of teaching. The process of interaction between middle managers and followers will be more effective with the establishment of constructive feedback environment in the workplace.

Perhaps the greatest limitation of this study is the nature of cross-sectional data, where data is collected at one specific point in time. A longitudinal study would provide greater supports for causality of feedback environment to self-efficacy of teaching. Further research is needed to explore how the relationships identified in this research are actually developed in higher education institutions. While we have a clearer picture of what managers have to be able to do in order to improve self-efficacy of teaching, we do not yet know how self-efficacy and feedback environment emerge 
and evolve in higher education institutions. The research model presented here could act as a springboard for more empirical studies in the future.

\section{References}

1. Aguinis, H., Gottfredson, R. K., \& Joo, H. (2012), "Delivering effective performance feedback: The strengths-based approach", Business Horizons, Vol 55, No. 2, pp. 105-111. https://doi.org/10.1016/j.bushor.2011.10.004

2. Bandura, A., \& Cervone, D. (1986), "Differential engagement of self-reactive influences in cognitive motivation", Organizational Behavior and Human Decision Processes, Vol. 38, No. 1, pp. 92-113. https://doi.org/10.1016/07495978(86)90028-2

3. Baron, R. M., \& Kenny, D. A. (1986), "The moderator-mediator variable distinction in social psychological research: Conceptual, strategic, and statistical considerations", Journal of Personality and Social Psychology, Vol. 51, No. 6, pp. 1173-1182. https://doi.org/10.1037/0022-3514.51.6.1173

4. Berg, M. E., \& Karlsen, J. T. (2012), “An evaluation of management training and coaching", Journal of Workplace Learning, Vol. 24, No. 3, pp. 177 - 199. https://doi.org/10.1108/13665621211209267

5. Bozer, G; Sarros, JC; Santora, JC. (2014), “Academic background and credibility in executive coaching effectiveness", Personnel Review, Vol. 43, No. 6, pp. 881 897. https://doi.org/10.1108/PR-10-2013-0171

6. Boyce, L.A., Jackson, J.R. and Neal, L.J. (2010), "Building successful leadership coaching relationships: examining impact of matching criteria in a leadership coaching program", Journal of Management Development, Vol. 29 No. 10, pp. 914-931. https://doi.org/10.1108/02621711011084231

7. Briggs, A. R. J. (2004) "Middle managers in further education colleges: The "New Professionals"", Journal of Educational Administration, Vol. 42, No. 5, pp.586 600. https://doi.org/10.1108/09578230410554089

8. Broad, M. and Goddard, A. (2010) "Internal performance management with UK higher education: an amorphous system?", Measuring Business Excellence, Vol. 14, No. 1, pp. 60 - 66. https://doi.org/10.1108/13683041011027454

9. Bowen, S. and Schofield, R. (2012), "Changing the Management Mindset to Manage Momentum in Higher Education: A Case Study", International Journal Of Learning, Vol. 18, No. 12, 243-258.

10. Buckingham, M., \& Clifton, D. O. (2001), Now, discover your strengths. New York: The Free Press.

11. Chen, Z., Lam, W., \& Zhong, J. A. (2007), "Leader-member exchange and member performance: A new look at the individual-level negative feedbackseeking behavior and team-level empowerment climate", Journal of Applied Psychology, Vol. 92, No. 2 202-212. https://doi.org/10.1037/0021-9010.92.1.202 
12. Cox, S. S., Marler, L. E., Simmering, M. J. and Totten, J. W. (2011), “Giving feedback: Development of scales for the mum effect, discomfort giving feedback, and feedback medium preference", Performance Improvement Quarterly, Vol. 23, No. 4, pp. 49-69. https://doi.org/10.1002/piq.20094

13. Dembo, M. H., \& Gibson, S. (1985), “Teacher's sense of efficacy: An important factor in school improvement", Elementary School Journal, Vol. 86, No. 2, pp. 173-184. http://www.jstor.org/stable/1001201

14. Department of Polyteclinic and Community College Education (2014), Department of Polyteclinic and Community College Education, Ministry of Higher Education Malaysia, available from: http://www.etawau.com/edu/Department/DPCCE.htm (accessed on 1 October 2015).

15. DeRue, D. and Wellman, N. (2009), “Developing Leaders via Experience: The Role of Developmental Challenge, Learning Orientation, and Feedback Availability", Journal Of Applied Psychology, Vol. 94, No. 4, pp. 859-875. https://doi.org/10.1037/a0015317

16. Economic Planning Unit (EPU) (2015), Strategy Paper 9 : Transforming Technical and Vocational Education and Training to Meet Industry Demand, Putrajaya: EPU, available from: http://rmk11.epu.gov.my/pdf/strategypaper/Strategy\%20Paper\%2009.pdf (accessed on 1 October 2015)

17. Fedor, D. B., Eder, R. W., \& Buckley, M. R. (1989), "The contributory effects of supervisor intentions on subordinate feedback responses", Organizational Behavior and Human Decision Processes, Vol. 44, No. 3, pp. 396-414. https://doi.org/10.1016/0749-5978(89)90016-2

18. Heslin, P. A., VandeWalle, D., \& Latham, G. F. (2006), 'Keen to help? Managers' implicit person theories and their subsequent employee coaching", Personnel Psychology, Vol. 59, No. 4, pp. 871-902. https://doi.org/10.1111/j.17446570.2006.00057.x

19. Hoy, W. K., \& Tschannen-Moran, M. (2003). The conceptualization and measurement of faculty trust in schools: The omnibus T-scale. In W. K. Hoy \& C. G. Miskel (Eds.). Studies in leadership and organizing school, Greenwich. CT: Information Age Publishing, pp. 181-208

20. Ilgen, D. R., \& Moore, C. F. (1987), "Types and choices of performance feedback", Journal of Applied Psychology, Vol. 72, No. 3, pp. 401-406. https://doi.org/10.1037/0021-9010.72.3.401

21.Jex, S. M., \& Britt, T. W. (2008), Organization psychology: A scientistpractitioner approach, $2^{\text {nd }}$ ed., New Jersey: John Wiley \& Sons, Inc.

22. Kluger, A. N., \& DeNisi, A. (1996), "The effects of feedback interventions on performance: A historical review, a meta-analysis and a preliminary feedback intervention theory", Psychological Bulletin, Vol. 119, No. 2, pp. 255-284. https://doi.org/10.1037/0033-2909.119.2.254 
23. Levy, P. E., \& Williams, J. R. (2004), "The social context of performance appraisal: A review and framework for the future". Journal of Management, Vol. 30, No. 6, pp. 881-905. https://doi.org/10.1016/j.jm.2004.06.005

24. Morrison, E. W. (1993), "Longitudinal-study of the effects of information seeking on newcomer socialization", Journal of Applied Psychology, Vol. 78, No. 2, pp. 173-183. https://doi.org/10.1037/0021-9010.78.2.173

25. Mustapha, R. B. (2001), "The Best Practices for Professional Development of Vocational Educators in Teaching Competencies among APEC Economies: A Case Study of Malaysia", Paper presented at the Seminar on the Best Practices for Professional Development of Vocational Teachers among Asia Pacific Economic Cooperation (APEC) Economies, Chiangmai, Thailand, June 20-22, 2001, available from: http://files.eric.ed.gov/fulltext/ED462574.pdf (accessed on 1 Oct 2015).

26. Nae, E. Y., Moon, H. K., \& Choi, B. K. (2015), "Seeking feedback but unable to improve work performance? Qualified feedback from trusted supervisors matters", Career Development International, Vol. 20, No. 1, pp. 81-100. https://doi.org/ 10.1108/CDI-08-2014-0107

27. Performance Management and Delivery Unit (PEMANDU) (2010), Economic Transformation Programme: a roadmap for Malaysia, Putrajaya: Performance Management and Delivery Unit (PEMANDU).

28. Shannon, D. M., Twale, D. J., \& Moore, M. S. (1998), “TA teaching effectiveness: The impact of training and teaching experience", Journal of Higher Education, Vol. 69, No. 4, pp. 440-446.

29. Sommer, K. L., \& Kulkarni, M. (2012), "Does constructive performance feedback improve citizenship intentions and job satisfaction? The roles of perceived opportunities for advancement, respect, and mood", Human Resource Development Quarterly, Vol. 23, No. 2, pp. 177-201. https://doi.org/10.1002/hrdq.21132

30. Spry, D. (2010), Cognitive behavioral coaching pocketbook. UK: Management Pocketbooks Ltd.

31. Steelman, L. A., Levy, P. E., \& Snell, A. F. (2004), “The feedback environment scale: Construct definition, measurement, and validation", Educational and Psychological Measurement, Vol. 64, No. 1, pp. 165-184. https://doi.org/10.1177/0013164403258440

32. Stewart, L. J., \& Palmer, S. (2009), "Capitalizing on coaching investment: Enhancing coaching transfer", Development and Learning in Organizations: An International Journal, Vol. 23, No. 3, pp. 14-17.

33. Thach, E. C. (2002), "The impact of executive coaching and 360 feedbacks on leadership effectiveness", Leadership \& Organization Development Journal, Vol. 23, No. 4, pp. 205-214. https://doi.org/10.1108/01437730210429070 
34. Tschannen-Moran, M., \& Hoy, A. W. (2001), "Teacher efficacy: Capturing an elusive construct", Teaching and Teacher Education, Vol. 17, No. 7, pp. 783-805. https://doi.org/10.1016/S0742-051X(01)00036-1

35. Tschannen-Moran, M., Hoy, A. W., \& Hoy, W. K. (1998), "Teacher efficacy: Its meaning and measure", Review of educational research, Vol. 68, No. 2, pp. 202248. https://doi.org/10.3102/00346543068002202

36. Wanberg, C. R., \& Kammeyer-Mueller, J. D. (2000), "Predictors and outcomes of proactivity in the socialization process", Journal of Applied Psychology, Vol. 85, No. 3, pp. 373-385. https://doi.org/10.1037/0021-9010.85.3.373

37. Westerman, C.; Heuett, K. B.; Reno, K. M. and Curry, R. (2014), "What Makes Performance Feedback Seem Just? Synchronicity, Channel, and Valence Effects on Perceptions of Organizational Justice in Feedback Delivery", Management Communication Quarterly, Vol. 28, No. 2, pp. 244-263. https://doi.org/10.1177/0893318914524060

38. Williams, J. R., Miller, C., Steelman, L. A., \& Levy, P. E. (1999), "Increasing feedback seeking in public contexts: It takes two (or more) to tango", Journal of Applied Psychology, Vol. 84, No. 6, pp. 969-976. https://doi.org/10.1037/00219010.84.6.969

39. Whitaker, B., \& Levy, P. (2012), "Linking feedback quality and goal orientation to feedback seeking and job performance", Human Performance, Vol. 25, No. 2, pp. 159-178. https://doi.org/10.1080/08959285.2012.658927

40. Young, S., \& Steelman, L. (2014), "The role of feedback in supervisor and workgroup identification”, Personnel Review, Vol. 43, No. 2, pp. 228-245. https://doi.org/10.1108/PR-01-2013-0006

41. Zajacova, A., Lynch, S. M., \& Espenshade, T. J. (2005), "Self-efficacy, stress, and academic success in college", Research in Higher Education, Vol. 46, No. 6, pp. 677-706. https://doi.org/10.1007/s11162-004-4139-z 